\title{
Theoretical Study of the Mind Map Notes
}

\author{
Ding Jingjing \\ Economics and Management School of Wuhan University, Wuhan, China \\ Jingjingding7@gmail.com
}

\begin{abstract}
Mind map uses pictures combined with words to make notes, significantly different from traditional notes. And it is popular among a variety of professionals and organizations abroad. China has witnessed nearly a decade's mind map craze, but the promotion effect is slender. Because theoretical researches are not thorough enough, the application tends to be formal, superficial, affecting the mind map's application effect. This paper studies the principle of using mind maps, including that image is the language of the brain, the neurons' structure, learn the new by the help of existing knowledge, whole brain learning and forgetting curve principle to guide notes drawing. And inspect the applying effect through empirical study on economics study.
\end{abstract}

Keywords: brain language; brain structure; learn the new by the help of existing knowledge; whole brain learning; forgetting curve

\section{I . The research status at home and abroad}

\section{The foreign research status}

Tony buzan wrote a mind map series in 1999, which introduced the features of mind maps, rendering, and application fields. Mind map as a form of note firstly was introduced into the world top 500 enterprises, into the meeting, management, report, etc, playing an important role. Thereafter it was introduced into primary and secondary school education and is paid higher attention to.

\section{The domestic research status}

In papers found before 1999, mind map is understood as a "guide map" [1], a kind of teaching "plot" [3], stirring students' learning motivation by relevant images ,training students' positive thinking and active participation ability [4]. The mind map discussed now is based on "the BBC Tony buzan intelligence series" [6] That same year, China has also introduced the concept of concept map, to some extent, confusing people's perception of mind map. Wang Gongling on the "heilongjiang science and technology information" first introduced the theoretical basis of mind maps and production procedures, notes and map method applied in writing lesson plans in 2000 [7]. Xu Liang in 2001 for the first time through the schema theory in cognitive linguistics, Combing the creation of mind maps in theory, pointing out that "Mind's radioactive structure broke the linearized model of logic language information, more intuitive naturally reflecting the proper connections between key concepts." [8] In 2004, Zhao Guoqing and Liu Zhijian have carried on the contrast analysis of mind map and concept map produced from the origin field and the possibility of integration [9], further defining the concept of mind map, marking the mind map studys real start. In 2011 Beijing Normal University published ,’Mind map and Study" introducing mind map and study on the five learning technology applying mind map to understand and solve the practical problems in college students' learning and life [11].It is China's first books about mind map application.

3 Literature review and innovations

There are few foreign literatures into China and they are out of the actual situation of China. And domestic researches about mind map in recent years, are on the rise but have broad and vague theoretical interpretation, particularly in the field of application of mind map notes and lack effective inspection theory research and practice. This paper clarifies the mind map notes theory in the field of application combined with the example, and give specific guidance to the application of mind maps .

\section{The principle of the effectiveness of the mind map}

\section{A. Introduction to mind map}

\section{The structure of the mind map}

A mind map is a radial image with a core, using graphic skills, and shows relationship of the topic at all levels with related hierarchy diagram, which creats a linkage between the subject keywords and images, color, etc.

\section{The advantages of mind map notes}

Because mind map and traditional notes have a huge difference in structure, the results of applying the two ways correspondingly vary widely. Compared with the traditional notes, the key impacts created by using mind map notes are as follows:

1.1 Priority. A mind map doesn't require students to record text line by line, but record the main points in the form of a keyword, and classifies them with radial lines, joining knowledge points with elements like lines .

1.2 Save time and improve efficiency. on the one hand, saving $80 \%$ of time to take notes; When reviewing on the other hand, one can form a structure of every piece of knowledge in mind, only to review the key words to save $90 \%$ of time; Moreover it enhances the use of the right brain, greatly increasing the speed and depth of memory. Keywords of the mind map are listed in time and space, flexibly combined to improve creativity and memory. Making mind map notes can enhance the students to explore new things, which stimulats students' motivation to learn.

\section{B. Theoretical analysis on the effectiveness of mind map}

\section{The image is the language of the brain}

Based on the feature of people's love for nature, Buzan thinks that image is language of brain, mind map helps us think with brain's own language so that brings us super memory and creativity. Drawing mind map is training the right brain. [11]. 
That pictures instead of text is emphasized is based on the following reasons:

1.1 Compared with text, images have advantage of containing larger amount of information

By comparison of the two graphs below we can see intuitively that images can make use of multi-dimensional, symbols, and other elements to enhance the performance capabilities to contain more information.

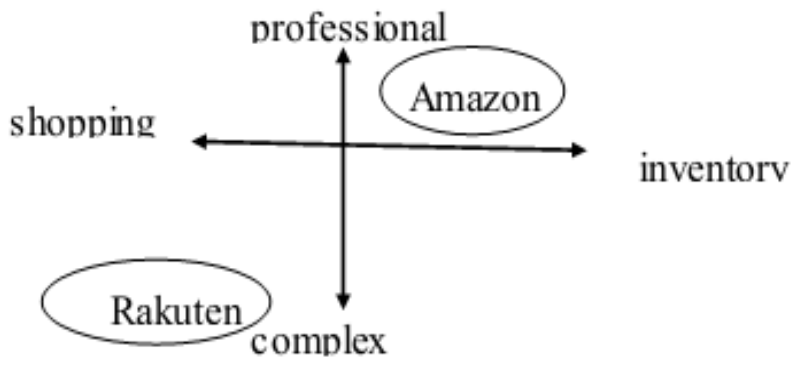

The difference bet ween Amazon and Rakuten Ichiba business model In Japan, although Amazon and Rakuten Ichiba are comparable, the mode of operation of the two varies differently. Rakuten is shopping street gathering shop, levying rental and Amazon has a large inventory and sales site. In addition, Rakuten Ichiba has wide range of business scope, from food to appliances, Amazon's main business scope is the book, $\mathrm{CD}$ and other media tools andappliances and other highly specialized areas.

Figure 1 Comparison of images and text in information [12]

1.2 Image memory is right brain memory whose speed of memory is a million times faster than left brain [6].

Using images can bring us exceptional memory, so we can memory a one hour's movie but simply having no memory of a ten minutes' articles. Having grasped the characteristics of memory we can purposefully improve the way of memory, and the way we make notes, using images instead of all text.

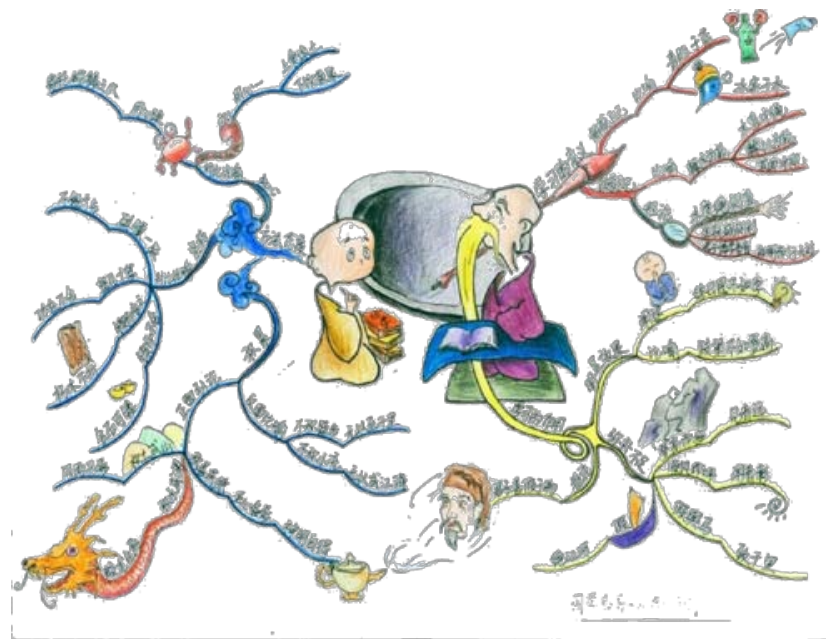

Figure 2 The mind map note of "Exhortation to Learning"[10]

\section{Neurons' structure}

Radioactive thinking is the core idea of making mind map. It simulates the structure of the human brain.

2.1 Mind map with radioactive structure can cultivate innovative thinking and ability.

2.1.1 From each perspective we can draw many branches, prompting us think innovatively. Take the core word "welfare" for example, we can think by adding words(welfare house), homonym(buoyancy), aggregate(Fuzhou pear), and replacement(RMB). So mind map note can also be applied in similar fields like essay writing, theme digging, problem solving and other things.

2.1.2 using mind maps to enhance the depth of thinking.

With unlimited expansion of branch mind map prompts the user to think more deeply.

\section{2 form a global view and the concept of center}

Radial structure helps users always maintain overall outlook "picture" of knowledge, which can give users a balanced overall comprehensive understanding of the subject. We can intuitively grasp the theme of the notes as well as relationships between various themes. Contact different branches achieved by the arrow lines. Each branch is both part of the whole, but also indie because of its unique color or the position brain, thereby avoiding the interference of information. According to Simon's "magic number 7" theory, the first rank of branches should be limited into seven.

\section{Construction of the brain database}

Whether the leading memory brain is the left brain or not, the efficient way of memory is to memory with help of prior knowledge. People often use the left brain to understand better by using prior knowledge; while right brain get effective memory by using pictures or story to create link with prior knowledge .

Mind map's each joint point can be another central theme, and then extends to tens of thousands of joint. These joints can be regarded as the user's existing memory. Divergent layout allows any filling. Connecting new information with old information proper expands one's brain database.

\section{Left and right brain work together}

The function of left brain focuses on language, logic, mathematics, order symbols and analysis. The right brain is focused on rhythm, drawing, imagination, emotion and creativity. The mind map notes are product of use of both. Use the left brain to get logic division, as well as the extraction of key words; and adding color, images, feelings and other elements to strengthen speed and effectiveness of memory.

\section{Forgetting curve Review}

Ebbinghaus found forgetting begins after learning immediately, and the process of forgetting is not uniform. Initially very quickly, and then gradually slow. According to the results of his experiment, he drew the Ebbinghaus forgetting curve. 


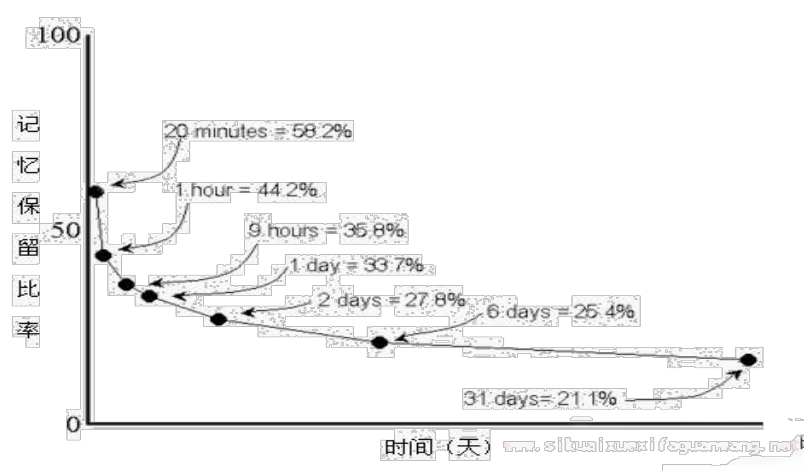

Figure 3 Ebbinghaus forgetting curve

According to the the Ebbinghaus curve, we can get review time:

1. First memory cycle: 5 minutes; 2 . Second cycle: 30 minutes; 3 . Third cycle: 1 day; 4 . Fourth cycle: two days;5. Fifth cycle: 7 days; 6 . Sixth memory cycle: 30 days

\section{The experiment}

How to draw mind map notes

Step1: paint core pictures which is related to main content in the center of paper.

Step 2: draw branches and write keywords on them,not under or beside them. Key words should be concise, usually less than four words ; different branches of the module using a different color.

experiment

Experiment: the whole book reading effect test

Experimental Process: 10 volunteers from different professional were divided into A, B groups and read the same book "currency war". A group had mastered how to use mind map notes, however B group hadn't. After 3 hours ask them questions about the framework and content of the book.

Experimental results: group A students drew a mind map. They had a clear grasp of the overall framework of the book and remember lots of knowledge. In comparison, group B students simply remember part of the knowledge, and felt hard to form all-sided comprehension

\section{Summary}

Mind map notes are different from the traditional linear notes on the construction and the principle. Mind map makes full use of the right brain's super memory by applying pictures and text and radioactive structure helps to form a clear overall sense of connection of the old and new knowledge .At the same time mind map expands knowledge, and coupled with the extraction of key words helps left brain to promote logic analysis capability. Many volunteers use the mind map notes and confirm the good efficacy of the mind map notes. Mind map can also be used for work, learning and living in any area. As individuals: planning, project management, communication, organization, analysis and problems solving; as learners: memory, notes making, reports writing, presentations, examinations; as professionals: plan, communication , project management, organization, holding meetings, training, negotiation, interviewing, assessment, brainstorming. All of these applications can greatly improve the efficiency and enhance the effectiveness and accuracy of the thinking and to enhance users' attention and fun.

\section{References}

[1] PangTianyi, "Efficacy and Application of Language illustrations" . Yancheng Teachers College: Humanities and Social Sciences, 1990, (3).

[2] Ye Changchun , " An effective tool to develop thinking ability" Secondary Language, 1991, (Z1).

[3] Zhang Shuxian , "Teaching Try in Geography Board Figure teaching" Chifeng Institute of Education, 2000, (2).

[4] Huang Zhengxing, "Pictures • Reading • Lecture - Learning Sentence by Pictures " Teaching Reference, 1995 (Z1).

[5] Hu Xingsong, "Ten Theories about Ideological and Political Teaching” .Secondary Political Teaching Reference, 1995, (5).

[6] Tony Buzan , "Intelligence Books Series" . Automotive Repair and Maintenance, 1999, (5).

[7] Wang Gongling , "Mind Map Pedagogy"'" . Heilongjiang Science and Technology Information, 2000, (4).

[8] Xu Liang, "Inspiration by Language Acquisition Neural Mechanisms of Gender Differences to Optimize Second Language Acquisition Strategy Comment on Tony Buzan radioactive thinking map principle". Foreign Language Teaching, 2001, (6) .

[9] Zhao Guoqing, Lu Zhijian , "Discrimination betweenCncept Map' and 'Mind Map' " China Educational Technology, 2004, (8).

[10] YuanWenkui, "Memory Magician", Chemical Industry Press, Beijing, 2012 (1).

[11] Lilin Ying , "Mind Map and Learning", Beijing Normal University Press, Beijng

[12] Yong Feng Tian Kai ,"Graphic Thinking" Technique ", Dragon Bookstore, Beijing, 2006 (1).

[13] Edwar·Da·Barnes, " Send You Six Hat", Sichuan University Press, 2003 (1).

[14] John·Adair, "Art of Creative Thinking", Renmin University of China Press, 2009 (1). 